R. Kubalek

A. Berlis

M. Schwab

J. Klisch

M. Schumacher

\section{Activated clotting time or activated partial thromboplastin time as the method of choice for patients undergoing neuroradiological intervention}

R. Kubalek $(\bowtie)$

Department of Neurology,

Academic Teaching Hospital Harlaching,

Sanatoriumsplatz 2, 81545 München,

Germany

E-mail: rkubalek@web.de

Tel.: + 49-89-62102257

Fax: + 49-89-62102453

A. Berlis · J. Klisch · M. Schumacher

\section{R. Kubalek}

Section of Neuroradiology,

University Hospital Freiburg,

Freiburg, Germany

M. Schwab

Roche Diagnostics, Mannheim,

Germany

\author{
Abstract We evaluated the role of \\ the activated clotting time (ACT) \\ and activated partial thromboplastin \\ time (APTT), both currently avail- \\ able as bedside tests, for monitoring \\ anticoagulation following bolus \\ injection of 2500 or 5000 IU heparin \\ in 21 patients undergoing neurora- \\ diological procedures. APTT was \\ measured using the CoaguChek Pro \\ device compared to the laboratory \\ standard measurement and ACT \\ comparing CoaguChek Pro to \\ Hemochron Celite and Kaolin. Sta- \\ tistical analysis was performed using \\ Bablok-Passing regression. Despite \\ heparin doses of 2500-5000 IU \\ APTT measurements were out of \\ range in $67 \%$ of patients using \\ CoaguChek Pro and in $76.5 \%$ of
}

patients using the laboratory measurement. ACT was reliably determined in all patients. The correlation between the different devices (CoaguChek Pro vs. Hemochron Celite $r=0.69$, Kaolin $r=0.78$ ) and assays (Hemochron Celite/Kaolin $r=0.85$ ) was good. ACT ranged from 141417 s measured by CoaguChek Pro and $138-320$ s measured by Hemochron Celite and 172-381 s using Hemochron Kaolin. These results indicate that ACT is the method of choice for monitoring anticoagulation in neuroangiographic procedures.

\section{Keywords Activated clotting} time $\cdot$ Activated partial thromboplastin time $\cdot$ Neuroradiology

\section{Introduction}

Heparin is routinely given intravenously to reduce the risk of thromboembolic complications in neuroangiography $[1,2,3]$. There are generally two ways of monitoring anticoagulation: the activated partial thromboplastin time (APTT) and the activated clotting time (ACT). The former is currently the most commonly used to monitor clinical heparin therapy despite its loglinear relationship to heparin dose and individual patient variations $[4,5,6]$. ACT is used to monitor anticoagulation during cardiopulmonary bypass and cardiac catheterisation procedures requiring large ( $\geq 10000$ IU) bolus injections of heparin, since it provides reliable data at higher heparin doses, with a linear relationship $[7,8,9,10,11]$. In the past, determination of the APTT required a laboratory assessment with a turnaround time of $1-4 \mathrm{~h}[4,10]$, rendering it useless during procedures, when adjustments of anticoagulation have to be made within minutes. New point-of-care devices have been developed offering instant APTT measurements using one drop of blood, comparable to ACT techniques.

Since there is a higher risk of intracerebral bleeding in neuroradiological interventional procedures the boluses of heparin are in the range 2500-7500 IU aiming for an ACT $>200 \mathrm{~s}$, or $1.5-2.5$ times the initial value $[1,2]$, compared with $300-400 \mathrm{~s}$ for cardiac interventions $[8,9$, $11,12,13,14]$, the question arose whether APTT or ACT is better for monitoring the efficacy of anticoagulation at lower heparin doses. 


\section{Materials and methods}

We prospectively studied 21 consecutive patients, ten men and 11 women aged 19-74 years (mean 54 years), undergoing neuroradiological interventions such as embolisation of an arteriovenous malformation, coiling of an aneurysm, placement of a carotid stent or temporary occlusion of a carotid artery, from whom informed consent could be obtained. The study was approved by the local ethics committee. Heparin was given as a bolus of $2500 \mathrm{IU}$ (in seven patients) or $5000 \mathrm{IU}$ (in 14). Four patients received an additional bolus of $2500 \mathrm{IU}$ on the decision of the interventionalist when the ACT level measured on Kaolin was $<200$ s, so that the total dose of heparin was $7500 \mathrm{IU}$ in two patients. The blood samples were taken before and 2-10 minutes after administration of heparin, then between 50-160 minutes after the first injection; on each occasion $9 \mathrm{ml}$ blood was withdrawn via the arterial sheath and distributed onto the different devices.

ACT was measured with two independent CoaguChek Pro devices (Roche Diagnostics $\mathrm{GmbH}$ ) and an Automated Coagulation Timer Hemochron 801 (International Technidyne Corporation) with two channels. One channel was used for Celite and the other channel for Kaolin test tubes, respectively. APTT was measured from whole blood with a CoaguChek Pro device (Roche Diagnostics $\mathrm{GmbH}$ ) and from a citrate blood sample in the hospital laboratory using the Patrontin kit (Behring). In four patients no laboratory APTT could be obtained due to a failure in blood sampling.

The statistical analysis of correlation between the different devices and the assays was carried out using the Bablok-Passing regression.

\section{Results}

Prior to the intravenous bolus of heparin the APTT measured by the CoaguChek Pro device was $<18-35.7 \mathrm{~s}$ (mean $27.4 \pm 4.7 \mathrm{~s}$ ); the laboratory measurements were $26-38 \mathrm{~s}$ (mean $31.3 \pm 3.6 \mathrm{~s}$ ), with one failure in blood sampling. The baseline ACT measured with CoaguChek Pro was $<100-129$ s (mean $112 \pm 9$ s), compared to 92$158 \mathrm{~s}$ measured with Hemochron Celite (mean $124 \pm 16$ s) and 97-148 s with Hemochron Kaolin (mean $120 \pm 13 \mathrm{~s})$.

After the 2500 or $5000 \mathrm{IU}$ heparin bolus a useful APTT measurement was obtained in only seven $(33 \%)$ of the 21 patients using CoaguChek Pro; the remainder had an APTT >150 s. In the laboratory a definite APTT was obtained in four $(23.5 \%)$ of 17 patients, the value in the other 13 cases being $>160 \mathrm{~s}$. In four patients no result was obtained due to a failure of the blood sample. ACT after the heparin bolus were 141417 s (mean $222 \pm 67$ s) measured with CoaguChek Pro, 138-320 s (mean 199 $\pm 43 \mathrm{~s}$ ) using Hemochron Celite and $172-381 \mathrm{~s}$ (mean $229 \pm 52 \mathrm{~s}$ ) with Hemochron Kaolin.

Samples taken at the end of the procedure showed an APTT $>160 \mathrm{~s}$ in eight $(38.1 \%)$ of the 21 patients when measured with CoaguChek Pro; the others were 20.3$137.2 \mathrm{~s}$. Laboratory measurements yielded an APTT $>160 \mathrm{~s}$ in nine $(45 \%)$ of 20 patients (one sample being inadequate), the others being $27-88 \mathrm{~s}$. ACT at this stage was $104-233 \mathrm{~s}$ (mean $157 \pm 36 \mathrm{~s}$ ) measured with the CoaguChek Pro, 72-256 s (mean $164 \pm 46 \mathrm{~s}$ ) using the Hemochron Celite and 114-255 s (mean $167 \pm 38$ s) with Kaolin.

Correlation between the different devices and assays was good: that correlation between the APTT measured by CoaguChek Pro and the standard laboratory measurement was $r=0.87$ (slope $=0.94)$. The correlation of the ACT obtained with CoaguChek Pro and with Hemochron Celite was $r=0.69$ (slope 1.19) and with Hemochron Kaolin it was $r=0.78$ (slope 1.04). The correlation of Celite and Kaolin was $\mathrm{r}=0.85$ (slope 1.14).

\section{Discussion}

The risk of neurological complications in diagnostic cerebral angiography is $0.09-1 \%$, increasing with the age of the patient, atherosclerotic plaques, prior stroke and longer procedures $[15,16,17,18,19,20]$. To minimise the risk of interventional procedures heparin is given intravenously, since the risk is known to be substantially increased, up to $5.7 \%$ in endovascular coil embolisation, for example [21]. Monitoring of heparininduced anticoagulation is crucial to ensure its efficacy, to minimise complications and to reveal any lack of response.

The use of ACT during percutaneous angioplasty in cardiac laboratories is well established and it has been found to be superior to APTT, which tends to run out of the measurable range $[5,7,10,11]$. This is due to the large ( $\geq 10000$ IU) doses of heparin given, since an ACT $300-350 \mathrm{~s}$ is aimed for, to prevent formation of thrombus and ensure a safe procedure [8].

In neuroangiography the heparin boluses are mainly 2500-7500 IU, since there is a fear of cerebral haemorrhage $[1,2]$. The use of ACT for monitoring anticoagulation in these procedures was adopted slowly, despite the fact that the need for continuous monitoring is obvious. In the recent guidelines of the American Society of Interventional and Therapeutic Neuroradiology [22] ACT measurements are recommended for all endovascular neuroradiological procedures when heparin is given, but to date only three publications $[1,2,3]$ deal with this. The speed and ready availability of ACT compared to APTT have been emphasised in the past; the latter was unsuitable for neuroradiological procedures because of the time it took $[1,10,11]$. Since bedside measurements of APTT became available, we thought we should study the usefulness of both techniques at the lower heparin doses used in neuroradiology.

Both during and at the end of our procedures, the APTT could not be used to assess anticoagulation since in several patients the upper limit was exceeded in both 
bedside and laboratory testing. ACT was useful in the whole group. Our quantitative ACT findings detailed above are in good agreement with those of Kaluski et al. [13], who found a mean ACT of $185 \pm 19$ s (range 157$238 \mathrm{~s}$ ) after a single bolus of $2500 \mathrm{IU}$ heparin.

We found a good correlation between bedside and laboratory testing for APTT, our $r$ value of 0.87 being in agreement with the 0.89 found by Reiner et al. [5]. The bedside test has the advantage that it is easy to perform and there were no missing values due to failed blood sampling.
Correlation between the different ACT methods was moderate. However, the differences are easily explained by the different activators used in the assays and the different techniques of the devices. This has been shown, for example, by comparing the Hemochron and Hemo Tec (Medtronic) devices. The activators are also known to have a different potential at low doses of heparin [7, $12,23]$. Our results underline the importance of considering which device is used, when trying to establish a threshold ACT for neuroangiographic procedures, something which has not been done so far.

\section{References}

1. Berlis A, Schumacher M (1999) Antikoagulationskontrolle bei neuroradiologisch Interventionellen Eingriffen mit ACT. Fortschr Röntgenstr 170: 378-383

2. Fujii Y, Takeuchi S, Koike T, et al (1994) Heparin administration and monitoring for neuroangiography. AJNR 15: 51-54

3. Scott JA, Berenstein A, Blumenthal D (1986) Use of the activated clotting time as a measure of anticoagulation during interventional procedures. Radiology 158: 849-850

4. Simko RJ, Tsung FFW, Stanek EJ (1995) Activated clotting time versus activated partial thromboplastin time for therapeutic monitoring of heparin. Ann Pharmacother 29: 1015-1021

5. Reiner JS, Coyne KS, Lundergan CF, Ross AM (1994) Bedside monitoring of heparin therapy: comparison of activated clotting time to activated partial thromboplastin time. Cathet Cardiovasc Diagn 32: 49-52

6. Banez EI, Triplett DA, Koepke J (1980) Laboratory monitoring of heparin therapy. The effect of different salts of heparin on the activated partial thromboplastin time. Am J Clin Pathol 74: 569-574

7. Dougherty KG, Gaos CM, Bush HS, Leachman DR, Ferguson JJ (1992) Activated clotting times and activated partial thromboplastin times in patients undergoing coronary angioplasty who receive bolus doses of heparin. Cathet Cardiovasc Diagn 26: 260-263
8. Ogilby JD, Kopelman HA, Klein LW, Agarwal JB (1989) Adequate heparinisation during PTCA: assessment using activated clotting times. Cathet Cardiovasc Diagn 18: 206-209

9. Grill HP, Spero JE, Granato JE (1993) Comparison of activated partial thromboplastin time to activated clotting time for adequacy of heparin anticoagulation just before percutaneous transluminal coronary angioplasty. Am J Cardiol 71: 1219-1220

10. Varah N, Smith J, Baugh RF (1990) Heparin monitoring in the coronary care unit after percutaneous transluminal angioplasty. Heart Lung 19: 265270

11. Noureddine SN (1995) Research review: use of activated clotting time to monitor Heparin therapy in coronary patients. Am J Critical Care 4: 272-277

12. Ferguson JJ, Dougherty KG, Gaos CM, Bush HS, Marsh KC, Leachman DR (1994) Relation between procedural activated coagulation time and outcome after percutaneous transluminal coronary angioplasty. J Am Coll Cardiol 23: 1061-1065

13. Kaluski E, Krakover R, Cotter G, et al (2000) Minimal heparinization in coronary angioplasty- how much heparin is really warranted? Am J Cardiol 85: 953956

14. Narins CR, Hillegass WB, Nelson CL, et al (1996) Relationship between activated clotting time during angioplasty and abrupt closure. Circulation 93: 667671

15. Dion JE, Gates PC, Fox AJ, Barnett HJ, Blom RJ (1987) Clinical events following neuroangiography: a prospective study. Stroke 18: 997-1004
16. Earnest F, Forbes G, Sandok BA, et al (1984) Complications of cerebral angiography: prospective assessment of risk. Am J Roentgenol 142: 247-253

17. Grzyska U, Freitag J, Zeumer H (1990) Selective cerebral intraarterial DAS: complication rate and control of risk factors. Neuroradiology 32: 296-299

18. Heisermann JE, Dean BL, Hodak JA, et al (1994) Neurologic complications of cerebral angiography. AJNR 15: 14011407

19. Gabrielsen TO (1994) Neurologic complications of cerebral angiography. AJNR 15: 1408-1411

20. Kachel R, Jahn U, Schiffmann R, Basche S (1991) Komplikationen bei zerebraler Angiographie. Eine Studie über 6698 zerebrale Angiographien. Rev Med Chir Soc Med Nat Lasi 95: 97-105

21. Cronqvist M, Pierot L, Boulin A, Cognard C, Castaings L, Moret J (1998) Local intraarterial fibrinolysis of thromboemboli occurring during endovascular treatment of intracerebral aneurysm: a comparison of anatomic results and clinical outcome. AJNR 19: $157-165$

22. American Society of Interventional and Therapeutic Neuroradiology (2001) Standards of practice. AJNR [Suppl] 22: $\mathrm{S} 2$

23. Ferguson JJ, Dohmen P, Wilson JM (1995) Results of a national survey on anticoagulation for PTCA. J Inv Cardiol 7: 136 